\title{
Dynamic structures in evo-devo: From morphogenetic fields to evolving organisms
}

\author{
Johannes Faeger \\ Complexity Science Hub (CSH) Vienna, Austria \\ Centre de Recherches Interdisciplinaires (CRI), Paris, France
}

\begin{abstract}
Evolution does not act on particular stages in the life of an organism. Instead, it alters developmental processes and life cycles in response to environmental conditions to bring about phenotypic change. The structure of these processes determines evolvability, the capacity of organisms to adapt. These structures are intrinsically dynamic. The organisational principles underlying organisms and the morphogenetic fields that constitute their ontogeny actively remodel themselves over time. How this occurs, and how it influences the rate and direction of evolutionary change, are central questions for biology. They lead us to fundamentally reconsider the active role of organisms in evolutionary change, which raises the possibility of a new agent-based theory of evolution in which organisms and their perceived environments co-construct each other in a radically innovative dialectic dynamic.
\end{abstract}

\section{Evolving life cycles}

In order to achieve a modification in adult form or behaviour, evolution must alter the ontogenetic processes responsible for producing that form or behaviour (Bonner, 1974; Horder, 1989; Fusco, 2001; Amundson, 2005). If we do not understand ontogeny, we cannot arrive at a satisfactory explanation of phenotypic evolution. Our explanation will remain causally incomplete. This is called the causal completeness principle (Amundson, 2005), variously attributed to Goldschmidt and Waddington (Gilbert et al., 1996), Garstang (Raff, 1996), or de Beer (Johnston and Gottlieb, 1990). Arguably, it is the most fundamental assertion of evolutionary developmental biology (evo-devo), and its many structuralist historical predecessors (Amundson, 2005). 
Changes in ontogeny cause evolutionary change. What do I mean by "ontogeny" in this context? Often, the term is used interchangeably with "development." There are several problems with this. First, evolution can act at any point within the life cycle - the trajectory of an organism from coming into being to reproducing (and senescence beyond that if we consider life history strategies as evolving traits) (Fusco, 2001; Minelli, 2003, 2014). However, development (in the conventional sense of the term) is restricted to a specific time interval covering specific stages within the cycle. To make things worse, it is not evident where development ends or where it begins (this issue is extensively discussed in Minelli and Pradeu, 2014; see also Oyama 2000, Minelli, 2003, 2011, Pradeu et al., 2011). Multigenerational life cycles can be composed of several phases of development (DiFrisco 2019 this volume; Fusco 2019 this volume; Fusco and Minelli, in press). Finally and foremost, it is not only developmental processes that contribute to the successful closure of the life cycle. Therefore, I will use the term "ontogeny" in a general sense here to include the sum of all metabolic, physiological, developmental, and behavioural processes that contribute to such closure.

The life cycle is composed of numerous intricately interwoven ontogenetic processes (see, for example, Jaeger and Monk, 2015; Nicholson and Dupré, 2018). They come in diverse forms, involve various chemical and physical substrates, occur at a wide range of different time scales, and typically depend on the intraand extra-organismic environment. What all of these processes have in common is that they are transient and dynamic. They constantly arise from activities and interactions of other processes, transmuting, or fading as their lifetime expires and their contribution is achieved. Nothing remains constant in life. Static explanations, such as network graphs, are clearly inadequate to capture the ever-changing nature of ontogeny. Even phenotypes must ultimately be considered to be dynamic (Fusco, 2001). For this reason, we require genuinely processual explanations for ontogeny and phenotypic transitions. The evolution of ontogeny is a process consisting of processes within processes, a monumental dynamic hierarchy (Riedl, 1975; Riedl, 1977). In this chapter, I examine the structure of this hierarchy of processes and find that it itself is constantly changing over time. This has important conceptual and methodological repercussions for evo-devo.

\section{Morphogenetic fields as dynamical modules}

My structuralist approach aims to understand the organisational principles that define the space-time order of the generative processes underlying ontogeny (Waddington, 1957; Waddington, 1970; Thom, 1976; Oster and Alberch, 1982; Goodwin, 1982a,b; Webster and Goodwin, 1996; Goodwin, 1999). These organisational principles are captured by the structure of morphogenetic fields. The 
morphogenetic field was the main explanatory concept of classical embryology before its decline and eclipse during the second half of the 20th century (Goodwin, 1982a,b; Webster and Goodwin, 1996; Gilbert et al., 1996). Morphogenetic fields are not necessarily identifiable with specific cells or tissues. Instead, they describe the relations of various physico-chemical processes responsible for generating specific ontogenetic patterns. They are spatially and temporally bounded, with given initial and boundary conditions. Within each field, global order arises from local interactions. Like the magnetic fields that inspired them, they are able to maintain a global pattern under various perturbations, such as stochastic fluctuations, truncation or fusion of fields. Morphogenetic fields are organized in a hierarchical manner during ontogeny and interact with each other in various ways. Specific examples of morphogenetic fields include the primary embryonic field of insect segment determination (Akam, 1987; Rosenberg, 2009; Jaeger, 2009, 2011, 2012, 2018), or more specific organ-forming fields, such as the vulval field in nematodes (Hoyos et al., 2011; Félix and Barkoulas, 2012; Corson and Siggia, 2012), the field responsible for dorso-ventral patterning in the vertebrate neural tube (Dessaud et al., 2008; Balaskas et al., 2012, Zagorski et al., 2017), or Turing patterning generators, such as the one responsible for digit formation and growth of the vertebrate limb (Marcon and Sharpe, 2012; Raspopovic et al., 2014; Onimaru et al., 2016).

One central characteristic of morphogenetic fields is their robustness against many kinds of perturbations (Goodwin et al., 1993; Webster and Goodwin, 1996). This implies that they can be implemented by a wide range of molecular mechanisms, which differ between almost every individual organism. In other words, a field represents a class or population of individual ontogenetic mechanisms that all share an equivalent structure and parameters defining their patterning activity (Oster and Alberch, 1982; Goodwin, 1982a; Alberch, 1991). In this sense, the morphogenetic field closely resembles the concept of a developmental type, which has nothing to do with essentialist typology (Amundson, 2005; Wagner, 2014). Fields as developmental types are reliably and robustly accessible features of evolving species (robust in the sense of Wimsatt, 2007) that can be observed, measured, and/or inferred from empirical data (Jaeger and Crombach, 2012). They mediate the mapping of genotypic to phenotypic variation under the influence of the environment (Waddington, 1970; Burns, 1970; Oster and Alberch, 1982; Goodwin, 1982a,b; Alberch, 1991; Pigliucci, 2010), constituting what Waddington called the epigenotype (Waddington, 1942, 1953) (Fig. 1). While individual mechanisms map to a given field, parameters of the field will not correspond to any specific molecular configuration in turn. The relationship between mechanism and field is therefore asymmetric and degenerate - many mechanisms for 
one field - which implies that it is not sufficient to study ontogeny at the level of molecular mechanisms to understand developmental evolution. In addition, we must focus our attention on the level of the epigenotype: the morphogenetic field, with its defining structure and parameters (Waddington, 1957, 1970; Oster and Alberch, 1982; Goodwin, 1982a,b; Webster and Goodwin, 1996; Jaeger et al., 2015; Jaeger and Monk, 2015).

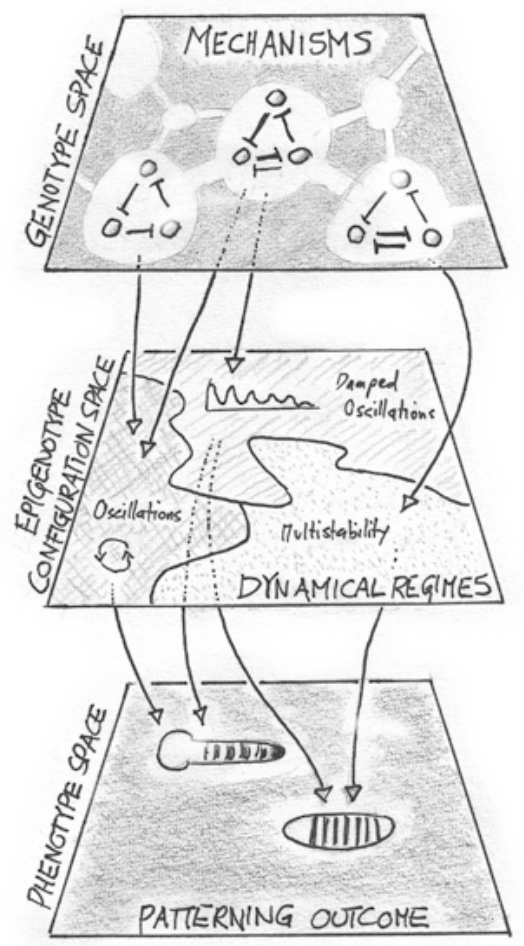

Figure 1. The epigenotype mediates the mapping from genotypic to phenotypic variation, determining the non-random probabilities of phenotypic transitions. Top: genotype space. Genotypes of individuals in evolving populations determine ontogenetic mechanisms through specific molecular implementations of gene regulatory networks. Each network differs in its molecular details. Mechanisms are connected by mutations, constituting what is called a "genotype network" (a meta-network of networks; Wagner, 2011). Middle: configuration space. Individual mechanisms map to regions of configuration space that correspond to specific dynamical regimes (e.g. oscillations, damped oscillations, or multistability, i.e. switch-like behaviour). The same mechanism can produce different dynamical regimes in different contexts, and different mechanisms can produce the same dynamical regime due to the degenerate asymmetrical relationship between molecular mechanisms and the control parameters defining the dynamical regime. Bottom: phenotype space. Different dynamical regimes, mediated by dynamical modules, combine in complex regulatory networks to produce a patterning outcome. Depending on the stability of the underlying dynamical regimes, random changes in molecular mechanisms lead to non-random probabilities of phenotypic transitions. 
Morphogenetic fields affect the rate and direction of evolution through their role in mapping genetic to phenotypic variation (Fig. 1). In this way, they determine the evolvability of an ontogenetic process, its capacity to produce adaptive change (Dawkins, 1989; Goodwin, 1982b; Wagner and Altenberg, 1996; Hendrikse et al., 2007; Pigliucci, 2008). The structure of the genotype-phenotype map determines the variational properties of a trait and, therefore, the probability of phenotypic transitions, providing a map of the possible underlying evolution by natural selection (Alberch, 1991; Wagner and Altenberg, 1996; Wagner, 2011; Francois and Siggia, 2012; Jaeger et al., 2012; Jaeger and Monk, 2014; Wagner, 2014; Jaeger et al., 2015).

I find one aspect of this structure particularly striking. The fact that ontogeny can be subdivided into individual morphogenetic fields - each responsible for a distinct observable dynamic pattern - implies a deep underlying dynamical modularity (Kauffman, 1993; Irons and Monk, 2007; Verd et al., 2018b; Jaeger, 2018). Modularity limits pleiotropic effects (Wagner and Alternberg, 1996; Wagner and Zhang, 2011), and is often seen as a prerequisite for adaptive evolution (Wagner and Altenberg, 1996; Raff, 1996; von Dassow and Munro, 1999; Schlosser and Wagner, 2004; Wagner et al., 2007; Callebaut and Rasskin-Gutman, 2007; Wagner, 2014). It allows us to identify components and interactions within a developmental process that contribute to a particular patterning activity, or dynamical regime (Irons and Monk, 2007; Verd et al., 2018b). Dynamical regimes represent qualitatively different types of patterning behaviour: Turing modes producing spots or stripes, for example (see, for example, Murray, 1981; Meinhardt, 1982; Meinhardt and Gierer, 2000; Murray, 2003; Kondo and Miura 2010; Marcon and Sharpe, 2012), or multistable switch-like behaviour (Monod and Jacob, 1961; Gardner et al., 2000; Wang et al., 2011; Furusawa and Kaneko, 2012, Ferrell, 2012, Verd and Jaeger, 2014), or the generation of damped or sustained oscillations and waves (Goodwin, 1963, Goodwin and Cohen, 1969, Goldbeter, 1997, Novak and Tyson, 2008; Maroto and Monk, 2009; Verd et al., 2018a).

The behaviour of distinct dynamical modules shows different degrees of robustness, or structural stability (Thom, 1976; Verd et al., 2018b). In other words, different modules show different sensitivities to structural changes: some are very robust, while others are in a state of criticality, which means that even small alterations in certain aspects of their structure can lead to large and abrupt changes in their dynamical behaviour. The system is poised on what Stuart Kauffman (1993) has called "the edge of chaos," likely to change its behaviour in certain ways, while maintaining it overall structural integrity. This is how dynamical modularity enables some evolutionary transitions while preventing others, therefore affecting the evolvability of ontogenetic processes and the phenotypes they generate (Verd et al., 2018b; Jaeger, 2018). 


\section{The dynamic structure of modular fields}

To understand the behaviour of a morphogenetic field, we must understand how its structure relates to the dynamics it can generate. We achieve this by using the powerful tools of dynamical systems theory (Hirsch et al., 2012; Strogatz, 2014). In this mathematical framework, the structure of the system is represented by a set of rules governing how it proceeds from its initial to its final state. Typical state variables for ontogenetic processes are concentrations of metabolites or gene products, signalling activities, membrane potentials, or other biophysical indicators such as cytoplasmic viscosity or tissue-level strain (see, for example, Noble, 2002; Forgacs and Newman, 2005; Jaeger, 2009; Jaeger et al., 2012; Kicheva et al., 2012; Morelli et al., 2012; Heisenberg and Bellaïche, 2013; Briscoe and Small, 2015; Gilmour et al., 2017), but they can also be abstract growth parameters modelling morphogenesis (e.g. McGhee, 2006; Mitteroecker and Huttegger, 2009). The rules governing change in these variables can be encoded by differential equations or logical rules. The precise mathematical formalism used is of no importance to our argument. What is important is that the rules determine the type and strength of regulatory interactions, the production rates and lifetimes of system components. In addition, the system must be bounded: we must specify which components and interactions are included (and which ones are left out), and we must define and limit the spatio-temporal domain over which the systems applies. Influences from outside the system must be given by boundary conditions. Internal rules and boundary conditions together represent the structure of the system.

The structure of the system determines the range of dynamical regimes it can generate, that is, its dynamical repertoire (Jaeger and Crombach, 2012; Jaeger and Monk, 2014; Strogatz, 2014; Jaeger et al., 2015). Nearly all biological regulatory systems are non-linear. This implies that small changes to the structure can lead to large changes in the repertoire. Dynamical regimes can be created or annihilated through bifurcations (Hirsch et al., 2012; Strogatz, 2014). Monostable systems have a very restricted repertoire with only one dynamical regime, while multistable systems can show a wide range of different behaviours depending on the initial conditions of the system. In any case, initial conditions and structure of the system together fully determine the dynamical behaviour of the system, given by its trajectory through state or configuration space (Thom, 1976; Jaeger et al., 2012; Jaeger and Monk, 2014; Strogatz, 2014; Verd and Jaeger, 2014; Jaeger et al., 2015).

On the one hand, this type of formalism is very powerful and well-suited for the study of modular morphogenetic fields. Equations and parameters not only define what the system does, but also what it can do under various circumstanc- 
es, and how it can change over time. On the other hand, the dynamical systems approach depends on two conditions that severely restrict its applicability in biology. First, we need to be able to precisely delimit the boundaries of the system. This is never an easy task. In reality, no module is an isolated system. Modularity is always a matter of degree. Herbert Simon called this widespread feature of complex systems near-decomposability (Simon, 1962, 1973). Which components and interactions to include in a module, and which to ignore, is often a matter of subjective judgment and depends on the nature of the problem being addressed (see, for example, Chu et al., 2003; Chu, 2011). Second, the structure of the system is assumed to remain constant over time. State variables change, but the parameters and rules governing their dynamics are supposed to remain constant. This assumption is rarely warranted in biology. Growth and tissue rearrangements alter the spatio-temporal domain. External factors - from inductive signals to changes in environmental conditions - modify the regulatory structure of morphogenetic fields (see, for example, Kicheva et al., 2012; Corson and Siggia, 2012; Verd and Jaeger, 2014; Verd et al., 2017). During ontogeny, fields arise and disappear, they split and merge (Goodwin, 1982a; Webster and Goodwin, 1996; Jaeger and Monk, 2015). This fundamental transience of ontogeny limits the applicability of the dynamical systems framework to short time frames, and only those modular fields that can be identified and bounded in space and time with reasonable precision.

Many difficulties arise, as soon as we look beyond this limited context. It becomes increasingly challenging to delimit the system precisely. The fact that its structure constantly changes raises the question at what point the system ceases to be the same process. And even though some mathematical tools exist to deal with time-dependent system structure (Mesarovic and Takahara, 1975; Rasmussen, 2007; Kloeden, 2011; Verd and Jaeger, 2014), it becomes increasingly difficult to accurately represent the changing structure of the system and analyse its behaviour in terms of dynamical systems theory. Although there is a growing sample of morphogenetic fields for which good models exist, we seem to be a long way away from understanding the complete ontogeny of any organism. This is not simply an empirical limitation, a matter of more research being done, but requires novel concepts and mathematical tools to deal with the transient and dynamic structure of ontogenetic processes.

\section{Organisms and organisational closure}

The problem gets much worse - or more interesting, depending on your point of view - once we consider whole organisms as dynamical systems (Varela et al., 1974; Varela, 1979; Varela et al., 1991; Rosen, 1991; Saunders, 1993; Gilbert 
and Sarkar, 2000; Gantí, 2003; Thompson, 2007; Moreno and Mossio, 2015). It is impossible to capture the causal structure, often called organisation, of a living organism with a formalism that requires a strict distinction between internal rules and boundary conditions or, in other words, a strict distinction between the system itself and its external environment. The reason for this is that organisms are not only bounded in space and time, but also show organisational closure (Piaget, 1967; Varela et al., 1974; Rosen, 1991; Letelier et al., 2011; Moreno and Mossio, 2015; Montévil and Mossio, 2015). Organisational closure reflects the fact that each part of an organism is both means and end, as both Aristotle and Kant already recognised. Not only does the whole owe its existence to its parts, but each part of an organism only exerts its function in the context and for the sake of the whole. This makes organisms fundamentally different from machines, or any other non-living system (Letelier et al., 2011; Nicholson, 2013, 2014). In fact, some authors have argued that closure is the defining characteristic of life (Varela et al., 1974; Rosen, 1991; Moreno and Mossio, 2015).

Organisational closure implies "mutual dependence between a set of constituents which could not exist in isolation, and which maintain each other through their interactions" (from Piaget, 1967, translated in Montévil and Mossio, 2015). Organisational closure is complementary to thermodynamic openness in living systems, and is directly related to the self-determination and agency of living beings (Jonas, 1966; Piaget, 1967; Varela et al., 1974; Varela, 1979; Ruiz-Mirazo and Moreno, 2004; Moreno and Mossio, 2015). Robert Rosen (1991), was the first to distinguish material and efficient causation in this context: material causes provide the chemical building blocks for the structure of the living system, efficient causes define its organisation. Organisms are open with regard to the former, but closed with regard to the latter. Every functional component of the organism's organisation is produced and maintained from within the system. This leads to autopoiesis - self-making, self-maintenance, and self-renewal of the system (Varela et al., 1974; Varela, 1979; Letelier et al., 2003) . Rosen (1991) used category theory to formally prove that systems closed to efficient causation cannot be captured by traditional mathematical formalisms such as dynamical systems theory.

Rosen's abstract top-down scheme for closure to efficient causation is not easy to map to actual biophysical cellular components (Letelier et al., 2003; Wolkenhauer and Hofmeyr, 2007; Piedrafita et al., 2010; DiFrisco, 2014; Hofmeyr, 2017). More recent work uses a bottom-up approach to link organisational closure to the underlying principles of far-from-equilibrium thermodynamics. It distinguishes between physico-chemical processes and their constraints, which determine how energy is released and propagated through a living sys- 
tem (Moreno and Ruiz-Mirazo, 1999; Kauffman, 2000; Ruiz-Mirazo and Moreno, 2004; Moreno and Mossio, 2015; Montévil and Mossio, 2015; Mossio et al., 2016). Such constraints are an essential component of the structure of a living system. They reduce the degrees of freedom of the processes on which they act, canalising energy flow into work-constraint cycles (Kauffman, 2000; Gantí, 2003). Catalytic enzymes are one important example of biological constraints: they alter the flow of metabolic processes without being affected by it, at least at the timescale of metabolism itself. On longer timescales, constraints need to be replaced, repaired, and maintained. This is achieved through mutual dependence: organisational closure can be interpreted as a closure of constraints, where each constitutive constraint in the system is both dependent on and generative of at least one other constraint (Fig. 2) (Moreno and Mossio, 2015; Montévil and Mossio, 2015). This leads to a system with an organisation that creates the conditions for its own continued existence (Moreno and Mossio, 2015; Mossio et al., 2016). The function of a component process is defined by its contribution to this self-maintaining dynamic (Mossio et al., 2009; Saborido et al., 2011; Moreno and Mossio, 2015). The autopoietic nature of the system, in turn, explains the autonomy, agency and self-determination of a living organism as the causes for its continued self-maintenance and -propagation are immanent within the system, not externally imposed on it (Varela et al., 1974; Varela, 1979; Bickhard, 2000; Christensen and Hooker, 2000; Moreno and Mossio, 2015; Mossio and Bich, 2017; Walsh, 2015, 2018).

In dynamical systems terms, constraints typically correspond to boundary conditions of the physico-chemical processes or subsystems that comprise a living system. Closure of constraints therefore implies that each constitutive boundary condition of an organism must be generated and maintained by other processes and their constraints within the system (Moreno and Mossio, 2015; Montévil and Mossio, 2015; Mossio et al., 2016). This creates two interesting problems when considering the entire organism as a dynamical system. First, closure of constraints leads to a system with is bounded, yet without constitutive boundary conditions, as these are now caused within the limits of the organism. Such a system cannot be encoded in terms of differential equations (Rosen, 1991).

More importantly in this context, the structure of the system - the rules governing processes and constraints - are constantly and radically changing. Self-maintenance is achieved through a fundamentally dynamic organisation, as constraints modify each other and keep on rerouting the underlying physico-chemical processes. Without this dynamic, closure cannot be achieved. Even worse, changes can be unpredictable. They can happen with many degrees of 
freedom as long as they do not disrupt the closure of constraints (see, Soto et al., 2016a; Mossio et al., 2016; Montévil et al., 2016a; Soto et al., 2016b, and other articles in the same special issue). Classical dynamical systems theory is ill-suited to represent such open-ended structural dynamics. If structure is allowed to change, it does so in predictable ways without closure (Rasmussen, 2007; Kloeden, 2011). Radically new approaches and methods will be required to capture this most fundamental aspect of evolving organisms in mathematical terms.

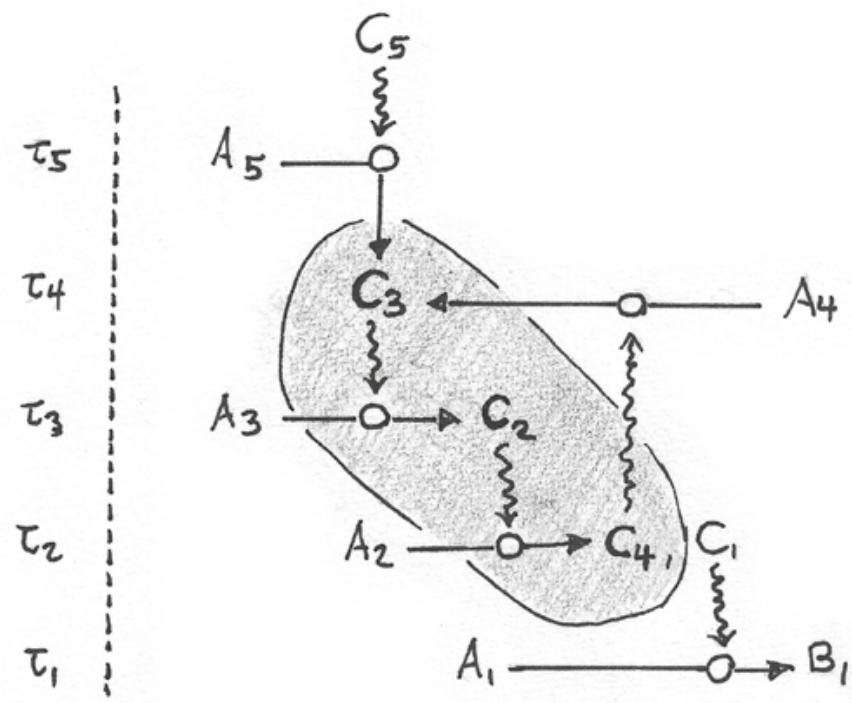

Figure 2. Organisational closure as closure of constraints. Physico-chemical processes are shown as solid arrows representing transformation of an input A to an output B. Constraints $\mathrm{C}$ act on these processes (wiggly arrows), redirecting energy flows. Constraints remain unaffected at the time scale of the constrained process ( $\tau$, column on the left). However, constraints can be generated by processes under constraints at different time scales. For instance, constraint $\mathrm{C}_{2}$ (the product of a process at time scale $\tau_{3}$ ) is dependent on $\mathrm{C}_{3}\left(\right.$ at $\left.\tau_{4}\right)$ and is generative of $\mathrm{C}_{4}$ $\left(\right.$ at $\left.\tau_{2}\right) . \mathrm{C}_{2}-\mathrm{C}_{4}$ form a network with organisational closure (indicated by grey background) as all constraints are accounted for by other constraints produced within the system. Organisationally closed systems are always materially and energetically open, indicated by their interactions with external processes and constraints that are not part of the system itself $\left(\mathrm{C}_{1}\right.$ and $\mathrm{C}_{5}$, for example). Diagram adopted from Montévil and Mossio, 2015; reproduced with permission.

\section{Dependent co-constitution}

The fact that organisms are dynamical systems generating their own constitutive boundary conditions has interesting consequences concerning the 
traditional notion of configuration space. Configuration space is an abstract multi-dimensional space defined by axes that consist of the system's state variables and parameters (Thom, 1976; Jaeger et al., 2015). In traditional dynamical systems theory, this space is pre-given: its geometry remains fixed, determined by externally imposed rules that govern the trajectory of the system through its configuration space. The idea that the world is structured in this way has been called the Newtonian paradigm by physicist Lee Smolin (2013), with the solar system as a classical example, where planets follow trajectories imposed on them by the laws of gravity. The dynamics of organisms are radically different, as the rules of change are immanent to the system: they originate with the self-determined activities of living beings and are constantly altered while the system unfolds (Varela et al., 1974, Varela, 1979; Varela et al., 1991; Rosen, 1991; Kauffman, 2000; Thompson, 2007; Letelier et al., 2011; Moreno and Mossio, 2015; Walsh, 2015). Subsystems are created or eliminated, state variables and parameters are reconfigured, as a consequence of the interplay between processes and their constraints within organisational closure. Put more directly, the very existence of the system and its configuration space become mutually dependent. This type of co-dependence goes far beyond mere mutual causation between two separately existing processes (Walsh, 2015, 2018). Neither the organism nor its configuration space exist without each other. They are dependently co-originated or co-constituted in a dialectical relationship through the autonomous activities of the living system (Lewontin and Levins, 1985; Walsh, 2015, 2018; Gilbert, 2018).

Autopoietic systems cannot exist without thermodynamic openness (Jonas, 1966; Piaget, 1967; Varela et al., 1974; Varela, 1979; Ruiz-Mirazo and Moreno, 2004; Moreno and Mossio, 2015; Montévil and Mossio, 2015), and a tight structural coupling with their environment (Varela et al., 1974; Varela, 1979; Varela et al., 1991; Thompson, 2007). The dialectical relationship presented above extends to this ecological realm. The experienced environment of an organism - also called umwelt (von Uexküll, 1909) or lebenswelt (Husserl, 1936) - is dependently co-constituted through the interactions of the living system with its surroundings (Thompson, 2007; Walsh, 2015). It is distinct from the physical environment and does not have any independent existence in the absence of the organism. Walsh (2015) illustrates this by comparing how paramecia and porpoises experience their aqueous environment. At the scale of the paramecium, locomotion through water takes the form of burrowing through a very viscous fluid. For the porpoise, moving is a problem of hydrodynamics and laminar flow. This leads to the evolution of very distinct locomotory strategies despite the fact that both organisms live in the same physical medium.

The outcome of evolution, ultimately, depends on a myriad of such individual interactions between organisms and their experienced environment (Walsh, 
2015, 2018). These interactions are fundamentally dialectic. Living agents perceive affordances (Gibson, 1986) - opportunities to pursue, or obstacles to avoid - that determine the success or failure of their autonomous actions. In this way, the organism and its experienced environment are intimately commingled (Walsh, 2015). The organism not only co-constitutes the boundary conditions that lead to organisational closure, but also those features of the environment that present opportunities for successful survival and reproduction. Hence, the distinction between the living system and its configuration space also breaks down at the level of its ecological interactions. Both ontogeny and evolution are governed by a fundamentally dialectical dynamic that depends on constant changes to its underlying structure. This leads to truly open and unpredictable evolutionary dynamics: novel dialectical interactions emerge at different moments in time - within the organism and between the organism and its experienced environment - resulting in a ceaseless exploration of what Stuart Kauffman calls the adjacent possible, a region of configuration space not only unexplored, but often also non-existent just a short moment before (Kauffman, 1996; Longo et al., 2012).

\section{Whither dynamical systems biology?}

My argument reveals a basic dilemma for current biology. On the one hand, dynamical systems theory is a powerful approach to study the behaviour of complex regulatory systems. On the other hand, traditional dynamical systems theory is fundamentally limited when dealing with the co-constituting dynamic structures of living systems. Using our current methods, we can only study subsystems with a very narrow scope. A radically new approach is needed to overcome this limitation.

Simulation-based studies, rather than mathematical analysis, offer a partial solution. Existing computational frameworks - such as agent-based modeling (see, for example, Klügl and Bazzan, 2012; Wilensky and Rand, 2015) and related approaches - allow us to implement evolving rules for the co-dependent emergence of system and configuration space. Unfortunately, there are two drawbacks. First, rules and context must still be provided externally, falling short of the radically immanent dialectic dynamics outlined above. The massive evolutionary simulation frameworks of artificial life, from Tierra (Ray, 1991) to Avida (Adami, 1998; Lenski et al., 2003), have met with limited success in capturing the truly open-ended innovative dynamic leading to ever-increasing complexity in evolution. Even these extremely ambitious and complex simulations are still missing essential aspects of evolving living systems. Second, purely simulation-based approaches become increasingly difficult to understand as their 
complexity increases. They expose us to the classic pitfall of systems biology: replacing a natural complex system we do not understand with a computational complex system we do not understand. Simulation generates prediction, but not necessarily insight. Our aim should not be to reproduce life in a computer, but to recognize and explain what life is and how it evolves in the natural world.

Ultimately, a deep understanding of living systems requires approaches that strike a compromise between analytical tractability and accuracy/completeness. It is not yet clear what such a theory would look like, but certain efforts point in the right direction. One example is René Thom's (1976) study of morphogenesis in terms of structural stability and bifurcations. Others are Robert Rosen's (1991) treatment of biological organisation using category theory, and Mesarovic and Takahara's (1976) generalisation of systems theory. These top-down theoretical efforts need to be combined with empirically grounded studies of particular ontogenetic systems, using novel modelling approaches and conceptual frameworks (see, for example, Verd and Jaeger, 2014; Montévil et al., 2016b; Verd et al., 2018a,b). This requires a serious and sustained trans-disciplinary effort of the research community. It poses a grand challenge for the life sciences in the 21st Century. Its aim is no less than to put the organism back at the heart of biology again.

\section{Acknowledgments}

I wish Sandro Minelli all the best for his $70^{\text {th }}$ birthday. That you may remain as productive as ever! I have greatly profited from your encyclopaedic knowledge throughout the years we have been running the Venice Summer School together. Grazie mille, Sandro, for your intellectual influence on my career and your continued support. I thank Berta Verd, whose modelling work and mathematical analyses catalysed my thinking about the fundamental time-variance of biological organisation and the limitations of dynamical systems theory. Many of the arguments in this chapter grew out of discussions we had about her work. I thank James DiFrisco, Nick Monk, Scott Gilbert, and Denis Walsh for discussions and comments on the manuscript. I thank Maël Montévil and Matteo Mossio for letting me use a caricature of their figure. I thank Jannie Hofmeyr who greatly helped me understand Robert Rosen's work, and Olaf Wolkenhauer who achieved the same for Mesarovic and Takahara. I am grateful to the many fellows and visitors who I had the pleasure to meet during my time at the Konrad Lorenz Institute (KLI). They introduced me to many new aspects of the topics discussed here. It was a wonderfully inspiring time. It is a shame it could not last. 


\section{References}

Adami, C. 1998. Introduction to artificial life. Springer, New York.

Akam, M. 1987. The molecular basis for metameric pattern in the Drosophila embryo. Development, 101: 1-22.

Alberch, P. 1991. From genes to phenotype dynamical systems and evolvability. Genetica, 84: 5-11.

Amundson, R. 2005. The changing role of the embryo in evolutionary thought. Cambridge University Press, Cambridge.

Bickhard, M.H. 2000. Autonomy, function, and representation. Communication and Cognition-Artificial Intelligence, 17: 111-131.

Bonner, J.T. 1974. On Development. Harvard University Press, Cambridge, MA.

Briscoe, J., Small, S. 2015. Morphogen rules: design principles of gradient-mediated embryo patterning. Development, 142: 3996-4009.

Burns, J. 1970. The synthetic problem and the genotype-phenotype relation in cellular metabolism. In: C.H. Waddington (ed.) Towards a theoretical biology, vol. 3. Aldine Publishing, Chicago, pp. 47-51.

Callebaut, W., Rasskin-Gutman, D. (eds.) 2005. Modularity: understanding the development and evolution of natural complex systems. MIT Press, Cambridge, MA.

Christensen, W.D., Hooker, C.A. 2000. Autonomy and the emergence of intelligence: organised interactive construction. Communication and Cognition-Artificial Intelligence, 17: 133-157.

Chu, D., Strand, R., Fjelland, R. 2003. Theories of complexity. Complexity, 8: 19-30.

Chu, D. 2011. Complexity: against systems. Theoretical Biosciences, 130: 229-245.

Corson, F., Siggia, E.D. 2012. Geometry, epistasis, and developmental patterning. Proceedings of the National Academy of Sciences U.S.A., 109: 5568-5575.

Dawkins, R. 1989. The evolution of evolvability. In: C. Langton (ed.) Artificial life: the proceedings of an interdisciplinary workshop on the synthesis and simulation of living systems. Addison-Wesley, Redwood City, pp. 201-220.

Dessaud, E. 2008. Pattern formation in the vertebrate neural tube: a sonic hedgehog morphogen-regulated transcriptional network. Development, 135: 2489-2503.

DiFrisco, J. 2014. Hylomorphism and the metabolic closure conception of life. Acta Biotheoretica, 62: 499-525.

DiFrisco, J. 2019. Homology and homoplasy of life cycle traits. In: G. Fusco (ed.) Perspectives on Evolutionary and Developmental Biology. Padova University Press, Padova, pp. 71-82.

Félix, M.-A., Barkoulas, M. 2012. Robustness and flexibility in nematode vulva development. Trends in Genetics, 28: 185-195.

Ferrell, J.E. 2012. Bistability, bifurcations, and Waddington's epigenetic landscape. Current Biology, 22: R458-R466.

Forgacs, G., Newman, S.A. 2005. Biological physics of the developing embryo. Cambridge University Press, Cambridge.

François, P., Siggia, E.D. 2012. Phenotypic models of evolution and development: geometry as destiny. Current Opinion in Genetics \& Development, 22: 627-633. 
Furusawa, C., Kaneko, K. 2012. A dynamical-systems view of stem cell biology. Science, 338: 215-217.

Fusco, G. 2001. How many processes are responsible for phenotypic evolution? Evolution \& Development, 3: 279-286.

Fusco, G. 2019. Evo-devo beyond development: the evolution of life cycles. In: G. Fusco (ed.) Perspectives on Evolutionary and Developmental Biology. Padova University Press, Padova, pp. 309-318.

Fusco, G., Minelli, A. in press. The Biology of Reproduction. Cambridge University Press. Gantí, T. 2003. The principles of life. Oxford University Press, Oxford.

Gardner, T.S., Cantor C.R., Collins, J.J. 2000. Construction of a genetic toggle switch in Escherichia coli. Nature, 403: 339-342.

Gibson, J.J. 1986. The ecological approach to visual perception. Psychology Press (Taylor \& Francis), New York.

Gilbert, S.F., Opitz, J.M., Raff R.A. 1996. Resynthesizing evolutionary and developmental biology. Developmental Biology, 173: 357-372.

Gilbert S.F., Sarkar S. 2000. Embracing complexity: organicism for the 21st century. Developmental Dynamics, 219, 1-9.

Gilbert, S. F. 2018. Achilles and the tortoise: some caveats to mathematical modeling in biology. Progress in Biophysics and Molecular Biology, 137: 37-45.

Gilmour, D., Rembold, M., Leptin, M. 2017. From morphogens to morphogenesis and back. Nature, 541: 311-320.

Goldbeter, A., 1997. Biochemical oscillations and cellular rhythms: the molecular bases of periodic and chaotic behaviour. Cambridge University Press, Cambridge.

Goodwin, B.C., 1963. Temporal organization in cells. Academic Press, New York.

Goodwin, B.C., 1969. A phase-shift model of the spatial and temporal organization of developing systems. Journal of Theoretical Biology, 25: 49-107.

Goodwin, B.C., 1982a. Development and evolution. Journal of Theoretical Biology, 97: 43-55.

Goodwin, B.C. 1982b. Biology without Darwinian spectacles. The Biologist, 29: 108-112. (reprinted in: C. Chetland, C. Millar, D. Lambert (eds.) 2013. The intuitive way of knowing: a tribute to Brian Goodwin. Floris Books, Edinburgh, pp. 45-54.)

Goodwin, B.C., Kauffman, S., Murray, J. D. 1993. Is morphogenesis an intrinsically robust process? Journal of Theoretical Biology, 163: 135-144.

Goodwin, B.C. 1999. D'Arcy Thompson and the problem of biological form. In: M.A.J. Chaplain, G.D. Singh, J.C. McLachlan (eds.) On growth and form: spatio-temporal pattern formation. John Wiley \& Sons, London, pp. 395-402.

Heisenberg, C.-P., Bellaïche, Y. 2013. Forces in tissue morphogenesis and patterning. Cell, 153: 948-962.

Hendrikse, J.L., Parsons, T.E., Halgrímsson, B. 2007. Evolvability as the proper focus of evolutionary developmental biology. Evolution \& Development, 9: 393-401.

Hirsch, M.W., Smale, S., Devaney, R. L. 2012. Differential equations, dynamical systems, and an introduction to chaos (3rd ed.). Academic Press, London.

Hofmeyr,J.-H.S.2017.Basicbiologicalanticipation.In:R.Poli(ed.)Handbookofanticipation: theoretical and applied aspects of the use of future in decision making. Springer, New York. https://link.springer.com/referencework/10.1007\%2F978-3-319-31737-3 
Horder, T.J. 1989. Syllabus for an embryological synthesis. In: D. B. Wake and G. Roth (eds.) Complex organismal functions: integration and evolution in vertebrates. Wiley, Chichester, pp. 315-348.

Hoyos, E., Kim, K., Milloz, J., Barkoulas, M., Pénigault, J.-B., Munro, E., Félix, M.-A. 2011. Quantitative variation in autocrine signaling and pathway crosstalk in the Caenorhabditis vulval network. Current Biology, 21: 527-538.

Husserl, E. 1936. Die Krisis der europäischen Wissenschaften und die transzendentale Phänomenologie. Rascher Verlag: Zürich, Leipzig. (English translation: Husserl, E. 1970. The Crisis of European Sciences and Transcendental Phenomenology. Northwestern University Press: Evanston, IL.j)

Irons, D.J., Monk, N.A.M. 2007. Identifying dynamical modules from genetic regulatory systems: applications to the segment polarity network. BMC Bioinformatics, 8: 413.

Jaeger, J. 2009. Modelling the Drosophila embryo. Molecuar BioSystems, 5: 1549-1568.

Jaeger, J. 2011. The gap gene network. Cellular and Molecular Life Sciences, 68: 243-274. Jaeger, J. 2018. Shift happens: the developmental and evolutionary dynamics of the gap gene system. Current Opinion in Systems Biology, 11: 65-73.

Jaeger, J., Crombach, A. 2012. Life's attractors: understanding developmental systems through reverse engineering and in silico evolution. In: O. Soyer (ed.) Evolutionary systems biology. Springer, Berlin, pp. 93-120.

Jaeger, J., Irons, D., Monk, N. 2012. The inheritance of process: a dynamical systems approach. fournal of Experimental Zoology B (Molecular Development and Evolution), 318: 591-612.

Jaeger, J., Laubichler, M., Callebaut, W. 2015. The comet cometh: evolving developmental systems. Biological Theory, 10: 36-49.

Jaeger, J., Manu, Reinitz, J. 2012. Drosophila blastoderm patterning. Current Opinion in Genetics \& Development, 22: 533-541.

Jaeger, J., Monk, N. 2014. Bioattractors: dynamical systems theory and the evolution of regulatory processes. Journal of Physiology, 592: 2267-2281.

Jaeger, J., Monk, N. 2015. Everything flows: a process perspective on life. EMBO Reports, 16: 1064-1067.

Johnston, T.D., Gottlieb, G. 1990. Neophenogenesis: a developmental theory of phenotypic evolution. Fournal of Theoretical Biology, 147: 100-112.

Jonas, H. 1966. The phenomenon of life: toward a philosophical biology. Northwestern University Press, Evanston, IL.

Kauffman, S.A. 1993. The origins of order: self-organization and selection in evolution. Oxford University Press, Oxford.

Kauffman, S.A. 1996. At home in the universe: the search for the laws of self-organization and complexity. Oxford University Press, Oxford.

Kauffman, S.A. 2000. Investigations. Oxford University Press, Oxford.

Kicheva, A., Cohen, M., Briscoe, J. 2012. Developmental pattern formation: insights from physics and biology. Science, 338: 210-212.

Kloeden, P. 2011. Nonautonomous dynamical systems. American Mathematical Society, Providence. 
Klügl, F., Bazzan, A.L. C. 2012. Agent-based modeling and simulation. AI Magazine, 33: 29-40.

Kondo, S., Miura, T. 2010. Reaction-diffusion model as a framework for understanding biological pattern formation. Science, 329: 1616-1620.

Lenski, R.E., Ofria, C., Pennock, R.T., Adami, C. 2003. The evolutionary origin of complex features. Nature, 423: 139-144.

Letelier, J.-C., Marín, G., Mpodozis, J. 2003. Autopoietic and (M,R) systems. fournal of Theoretical Biology, 222: 261-272.

Letelier, J.-C., Cárdenas, M.L., Cornish-Bowden, A. 2011. From L’Homme Machine to metabolic closure: steps towards understanding life. fournal of Theoretical Biology, 286: $100-113$.

Lewontin, R., Levins, R. 1985. Biology under the influence: dialectical essays on ecology, agriculture, and health. Monthly Review Press, New York.

Longo, G., Montévil, M., Kauffman, S. 2012. No entailing laws, but enablement in the evolution of the biosphere. In: T. Soule (ed.) GECCO 2012: Proceedings of the 14th annual conference on genetic and evolutionary computation. ACM, New York, pp. 1379-1392.

Maroto, M., Monk, N.A.M. (eds.) 2009. Cellular oscillatory mechanisms. Landes Bioscience, New York.

Marcon, L., Sharpe, J. 2012. Turing patterns in development: what about the horse part? Current Opinion in Genetics \& Development, 22: 578-584.

McGhee, G.R. 2006. The geometry of evolution: adaptive landscapes and theoretical morphospaces. Cambridge University Press, Cambridge.

Meinhardt, H. 1982. Models of biological pattern formation. Academic Press, London.

Meinhardt, H., Gierer, A. 2010. Pattern formation by local self-activation and lateral inhibition. BioEssays, 22: 753-760.

Mesarovic, M.D., Takahara, Y. 1975. General systems theory: mathematical foundations. Academic Press. New York.

Minelli, A. 2003. The development of animal form: ontogeny, morphology, and evolution. Cambridge University Press, Cambridge.

Minelli, A. 2011. Development, an open-ended segment of life. Biological Theory, 6: 4-15.

Minelli, A. 2014. Developmental disparity. In: A. Minelli, T. Pradeu (eds.) Towards a theory of development. Oxford University Press, Oxford.

Minelli, A., Pradeu, T. 2014. Towards a theory of development. Oxford University Press, Oxford.

Mitteroecker, P., Huttegger, S.M. 2009. The concept of morphospaces in evolutionary and developmental biology: mathematics and metaphors. Biological Theory, 4: 45-67.

Monod, J., Jacob, F. 1961. General conclusions: teleonomic mechanisms in cellular metabolism, growth, and differentiation. Cold Spring Habor Symposia on Quantitative Biology, 26: 389-401.

Montévil, M., Mossio, M. 2015. Biological organisation as closure of constraints. fournal of Theoretical Biology, 372: 179-191.

Montévil, M., Mossio, M., Pocheville, A., Longo, G. 2016a. Theoretical principles for biology: variation. Progress in Biophysics and Molecular Biology, 122: 36-50. 
Montévil, M., Speroni, L., Sonnenschein, C., Soto, A. M. 2016b. Modeling mammary organogenesis from biological first principles: cells and their physical constraints. Progress in Biophysics and Molecular Biology, 122: 58-69.

Morelli, L.G., Uriu, K., Ares, S., Oates, A. C. 2012. Computational approaches to developmental patterning. Science, 336: 187-191.

Moreno, A., Ruiz-Mirazo, K. 1999. Metabolism and the problem of its universalization. BioSystems, 49: 45-61.

Moreno, A., Mossio, M., 2015. Biological autonomy: a philosophical and theoretical enquiry. Springer, Dordrecht.

Mossio, M., Saborido, C., Moreno, A. 2009. An organizational account of biological functions. British fournal for the Philosophy of Science, 60: 813-841.

Mossio, M., Montévil, M., Longo, G. 2016. Theoretical principles for biology: organization. Progress in Biophysics and Molecular Biology, 122: 24-35.

Mossio, M., Bich, L. 2017. What makes biological organisation teleological? Synthese, 194: 1089-1114.

Murray, J.D. 1981. A pre-pattern formation mechanism for animal coat markings. Journal of Theoretical Biology, 88: 161-199.

Murray, J.D. 2003. Mathematical Biology (2nd ed.). Springer, New York.

Nicholson, D.J. 2013. Organisms $\neq$ machines. Studies in History and Philosophy of Biological and Biomedical Sciences, 44: 669-678.

Nicholson, D.J. 2014. The machine conception of the organism in development and evolution: a critical analysis. Studies in History and Philosophy of Biological and Biomedical Sciences, 48: 162-174.

Nicholson, D.J., Dupré, J. 2018. Everything flows: towards a processual philosophy of biology. Oxford University Press, Oxford.

Noble, D. 2002. Modeling the heart - from genes to cells to the whole organ. Science, 295: 1678-1682.

Novak, B., Tyson, J. J. 2008. Design principles of biochemical oscillators. Nature Reviews Molecular Cell Biology, 9: 981-991.

Onimaru, K., Marcon, L., Musy, M., Tanaka, M., Sharpe, J. 2016. The fin-to-limb transition as the re-organization of a Turing pattern. Nature Communications, 7: 11583.

Oster, G, Alberch, P. 1982. Evolution and bifurcation of developmental programs. Evolution, 36: 444-459.

Oyama, S. 2000. The ontogeny of information: developmental systems and evolution (2nd ed.). Duke University Press, Durham.

Piaget, J. 1967. Biologie et connaissance. Gallimard, Paris.

Piedrafita, G., Montero, F., Morán, F., Cárdenas, M.L., Cornish-Bowden, A. 2010. A simple self-maintaining metabolic system: robustness, autocatalysis, bistability. PLoS Computational Biology, 6: e1000872.

Pigliucci, M. 2008. Is evolvability evolvable? Nature Reviews Genetics, 9: 75-82.

Pigliucci, M. 2010. Genotype-phenotype mapping and the end of the 'genes as blueprint' metaphor. Philosophical Transactions of the Royal Society B, 365: 557-566.

Pradeu, T., Laplane, L., Morange, M., Nicoglou, A., Vervoort, M. 2011. The boundaries of development. Biological Theory, 6: 1-3. 
Raff, R.A. 1996. The shape of life. University of Chicago Press, Chicago.

Rasmussen, M. 2007. Attractivity and bifurcation for nonautonomous dynamical systems. Springer, Heidelberg.

Raspopovic, J., Marcon, L., Russo, L., Sharpe, J. 2014. Digit patterning is controlled by a Bmp-Sox9-Wnt Turing network modulated by morphogen gradients. Science, 354: 567-570.

Ray, T.S. 1991. An approach to the synthesis of life. In: C. Langton, C. Taylor, J. D. Farmer, S. Rasmussen (eds.) Artificial life II. Addison-Wesley, Redwood City, pp. 371-408.

Riedl, R. 1975. Die Ordnung des Lebendigen: Systembedingungen der Evolution. Parey, Hamburg/Berlin. (English translation: Riedl R. (auth.), Jeffries, R. P. S. (transl.) 1978. Order in living systems: a systems analysis of evolution. Wiley, New York.)

Riedl, R. 1977. A systems-analytical approach to macro-evolutionary phenomena. The Quarterly Review of Biology, 52: 351-370.

Rosen, R. 1991. Life itself: a comprehensive inquiry into the nature, origin, and fabrication of life. Columbia University Press, New York.

Rosenberg, M.I., Lynch, J.A., Desplan, C. 2009. Heads and tails: evolution of anteroposterior patterning in insects. Biochimica et Biophysica Acta, 1789: 333-342.

Ruiz-Mirazo, K., Moreno, A. 2004. Autonomy in evolution: from minimal to complex life. Synthese, 185: 21-52.

Saborido C., Mossio, M., Moreno, A. 2011. Biological organization and cross-generation functions. British fournal for the Philosophy of Science, 62: 583-606.

Saunders, P. 1993. The organism as a dynamical system. In: F. Varela, W. Stein (eds.) Thinking about biology. Addison-Wesley, Reading, MA.

Schlosser, G., Wagner, G.P. (eds.) 2004. Modularity in development and evolution. University of Chicago Press, Chicago.

Simon, H.A. 1962. The architecture of complexity. Proceedings of the American Philosophical Society, 106: 467-482.

Simon, H.A. 1973. The organization of complex systems. In: H.H. Pattee (ed.) The challenge of complex systems. George Braziller, New York, pp. 1-28.

Smolin, L. 2013. Time reborn: from the crisis in physics to the future of the universe. Houghton Mifflin Harcourt, Boston.

Soto, A.M., Longo, G., Montévil, M., Sonnenschein, C. 2016a. The biological default state of cell proliferation with variation and motility, a fundamental principle for a theory of organisms. Progress in Biophysics and Molecular Biology, 122: 16-23.

Soto, A.M., Longo, G., Miquel, P.-A., Montévil, M., Mossio, M., Perret, N., Pocheville, A., Sonnenschein, C. 2016b. Toward a theory of organisms: three founding principles in search of a useful integration. Progress in Biophysics and Molecular Biology, 122: 77-82.

Strogatz, S.H. 2014. Nonlinear dynamics and chaos: with applications to physics, biology, chemistry, and engineering (2nd ed.). Westview Press. Boulder.

Thom, R. 1976. Structural stability and morphogenesis. W.A. Benjamin, Reading, MA.

Thompson, E. 2007. Mind in life: biology, phenomenology, and the sciences of the mind. The Belknap Press of Harvard University Press, Cambridge, MA. 
Varela, F.J., Maturana, H. R., Uribe, R. 1974. Autopoiesis: the organization of living systems, its characterization and a model. BioSystems, 5: 187-196.

Varela, F.J. 1979. Principles of biological autonomy. North Holland (Elsevier), New York.

Varela, F.J., Thompson, E., Rosch, E. 1991. The embodied mind: cognitive science and human experience. MIT Press, Cambridge, MA.

Verd, B., Clark, E., Wotton, K. R., Janssens, H., Jiménez-Guri, E., Crombach, A., Jaeger, J. 2018a. A damped oscillator imposes temporal order on posterior gap gene expression in Drosophila. PLoS Biology, 16: e2003174.

Verd, B., Crombach, A., Jaeger, J. 2017. Dynamic maternal gradients control timing and shift-rates of Drosophila gap gene expression. PLoS Computational Biology, 13: e1005285.

Verd, B., Jaeger, J. 2014. Classification of transient behaviours in a time-dependent toggle switch. BMC Systems Biology, 8: 43.

Verd, B., Monk, N., Jaeger, J. 2018b. Modularity, criticality and evolvability of a developmental gene regulatory network. eLIFE, submitted. (Preprint available on bioarXiv: https://www.biorxiv.org/content/early/2018/09/10/413211).

von Dassow, G., Munro, E. 1999. Modularity in animal development and evolution: elements of a conceptual framework for EvoDevo. Fournal of Experimental Zoology B (Molecular Development and Evolution), 285: 307-325.

von Uexküll, J. 1909. Umwelt und Innenwelt der Tiere. Springer, Berlin.

Waddington, C.H. 1942. The epigenotype. Endeavour 1: 18-20. (reprinted in 2012: International fournal of Epidemiology, 41: 10-13.)

Waddington, C.H. 1953. Epigenetics and evolution. In: Symposia of the Society for Experimental Biology VII: Evolution. Cambridge University Press, Cambridge, pp. 186-199.

Waddington, C.H. 1957. The strategy of the genes: a discussion of some aspects of theoretical biology. Allen \& Unwin, London.

Waddington, C.H. 1970. The theory of evolution today. In: A. Koestler, J. R. Smythies (eds.) Beyond reductionism. MacMillan, New York.

Wagner, A. 2011. The origins of evolutionary innovations: a theory of transformative change in living systems. Oxford University Press, Oxford.

Wagner, G.P., Altenberg, L. 1996. Complex adaptations and the evolution of evolvability. Evolution, 50: 967-976.

Wagner, G.P., Pavlicev, M., Cheverud, J. M. 2007. The road to modularity. Nature Reviews Genetics, 8: 921-931.

Wagner, G.P., Zhang, J. 2011. The pleiotropic structure of the genotype-phenotype map: the evolvability of complex organisms. Nature Reviews Genetics, 12: 204-213.

Wagner, G.P. 2014. Homology, genes, and evolutionary innovation. Princeton University Press, Princeton.

Walsh, D.M. 2015. Organisms, agency, and evolution. Cambridge University Press, Cambridge.

Walsh, D.M. 2018. Objectcy and agency: towards a methodological vitalism. In: D.J. Nicholson, J. Dupré (eds.) Everything flows: towards a processual philosophy of biology. Oxford University Press, Oxford, pp. 167-185. 
Wang, J., Zhang, K., Xu, L., Wang, E. 2011. Quantifying the Waddingtonian landscape and biological paths for development and differentiation. Proceedings of the National Academy of Sciences U.S.A., 108: 8257-8262.

Webster, G., Goodwin, B. 1996. Form and transformation: generative and relational principles in biology. Cambridge University Press, Cambridge.

Wilensky, U., Rand, W. 2015. An introduction to agent-based modeling. MIT Press, Cambridge, MA.

Wimsatt, W.C. 2007. Re-engineering philosophy for limited beings: piecewise approximations to reality. Harvard University Press, Cambridge, MA.

Wolkenhauer, O., Hofmeyr, J.-H. S. 2007. An abstract cell model that describes the selforganization of cell function in living systems. Fournal of Theoretical Biology, 246: 461-476.

Zagorski, M., Tabata, Y., Brandenberg, N., Lutolf, M.P., Tkačik, G., Bollenbach, T., Briscoe, J., Kicheva, A. 2017. Decoding of position in the developing neural tube from antiparallel morphogen gradients. Science, 356: 1379-1383. 